\title{
Biochemical Characterization of Multiple Myeloma Patients across ISS Stages - A Data Base Workup from a Tertiary Care Hospital in India
}

\author{
Noorjahan Mohammed ${ }^{1}$, KSS SaiBaba ${ }^{1}$, Yadagiri.B ${ }^{1}$, Sadasivudu Gundeti ${ }^{2}$, Sree \\ Bhushan Raju ${ }^{3}$
}

${ }^{1}$ Department of Biochemistry, Hyderabad, Telangana, India 500082. ${ }^{2}$ Department of Medical Oncology, Hyderabad, Telangana, India 500082. ${ }^{3}$ Department of Nephrology, Nizam's Institute of Medical Sciences, Hyderabad, Telangana, India 500082.

\begin{abstract}
Background: Multiple myeloma (MM) is slowly becoming a huge medical burden, challenging the health-care systems of Asian countries. Because of the unavailability of widespread access to various modalities of investigations, and paucity of well compiled data on common presenting features and various laboratory parameters in various stages of MM in India, the diagnosis is usually delayed till complications begin to occur. This study is an attempt to fill this gap and to establish database for future reference. Methods: The study was conducted in a tertiary health care centre over a span of 3 years and 94 patients diagnosed as MM with complete workup including beta 2 microglobulin $(\beta 2 \mathrm{M})$, bone marrow plasma cell percentage, serum protein electrophoresis, serum and urine Immunofixation and serum Free Light Chains (FLC) were included. The various laboratory parameters were statistically analyzed across ISS stages I, II and III. Results: We found a male to female ratio of 1.47:1. The mean age of patients was $55.5 \pm 11.78$ yrs. Backache was the most frequent presentation (30\%) of the patients followed by generalized weakness $(22 \%)$. The percentage of plasma cells, hemoglobin, urea, creatinine, uric acid, calcium and $\beta 2 \mathrm{M}$ showed significant difference across the stages. $38.3 \%$ of the patients were in stage III,

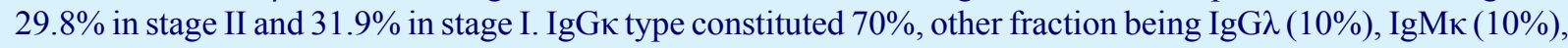
$\operatorname{IgA\kappa }(5 \%)$ and $\operatorname{IgA} \lambda(5 \%)$. M band was not seen in $11 \%$ of patients. Conclusion(s): The presentation of MM is nonspecific and patient can come with varied presentations at onset. We have biochemically characterized the three stages of MM and this will form a basis for further larger studies on these lines and to develop stage-based algorithms for early and better diagnosis and prognosis of MM.
\end{abstract}

Keywords: Multiple myeloma- stages- Beta 2 microglobulin- free light chains- India

Asian Pac J Cancer Care, 4 (3), 77-82

\section{Introduction}

Multiple myeloma (MM) is a disorder caused by neoplastic proliferation of a clone of malignant plasma cells. The incidence of myeloma is highest in African-American and Pacific islanders, intermediate in Europeans and North Americans and lowest in developing countries including Asia. The incidence of multiple myeloma (MM) is increasing rapidly in Asian countries. MM will eventually become a tremendous medical burden in this region, challenging the health-care systems of Asian countries. Because of huge disparities in economy,
Submission Date: 02/04/2019 Acceptance Date: 04/01/2019

lack of adequate health-care infrastructure and the lack of access to novel drugs in our country, treatment of MM is still a challenge to medical field in India. In India, the estimated incidence according to Globocan 2012 is 6955 new cases, mortality of 6027 and 5 years' prevalence estimate of 11886 [1].

MM comprises $13 \%$ of hematologic malignancies. The characteristic features of MM include accumulation of monoclonal plasma cells in the bone marrow associated with monoclonal immunoglobulin (Ig) synthesis and osteolytic bone lesions. The clinical features of the illness usually include bone pain, which is also a common

Corresponding Author:

Dr. KSS Sai Baba

Department of Biochemistry, Hyderabad, Telangana, India 500082.

Email:ksssaibaba@gmail.com 
presentation of other disease conditions in this peculiar age group. Complications such as renal failure, infections, anemia, lytic bone lesions and amyloidosis lead to morbidity as well as mortality [2]. Though most patients of $\mathrm{MM}$ are symptomatic at presentation needing prompt treatment, about $10-15 \%$ may remain asymptomatic in whom treatment may be delayed. This leads to delay in diagnosis as well as mis-referrals, which usually in the long run affect treatment outcome. A high index of suspicion by the physician is therefore important and may be informed by knowledge of the common presenting clinical symptoms. Evaluation of the common investigations, presenting features, especially in a resource poor and predominantly local population will serve as a guide and necessary aid to early diagnosis [3].

Raised calcium, renal impairment, anemia, and bone lesions (CRAB) are the currently accepted diagnostic criteria for diagnosis of symptomatic (and therefore treatable) myeloma. Although magnetic resonance imaging (MRI) and computed tomography/positron emission tomography (CT/PET) are very sensitive and may provide more information in certain cases, limited facilities as well as finances have limited the use of these diagnostic tools in resource poor settings where simple $\mathrm{X}$-ray of bone is still considered standard. Prognostic markers such as $\beta 2$ microglobulin may not be easily assayed in some parts of the country or affordable by some patients. However, to the unsuspecting physician, these investigations are not usually regarded as baseline and the diagnosis is usually delayed till complications begin to occur. It may therefore be necessary to have database of all these investigations to examine the patients in different stages of MM that actually have positive results with these laboratory modalities [3].There are very few studies related to MM in this regard from India.

This study therefore aims to describe the clinical and laboratory features associated with $\mathrm{MM}$ at various stages of presentation in this environment and establishing database for future reference.

\section{Material and Methods}

The study was conducted in a tertiary health care centre over a span of 3 years. We have included 94 cases of multiple myeloma which are diagnosed based on the International Myeloma Working Group (IMWG) diagnostic criteria for multiple myeloma [4]. The workup included serum urea and creatinine, serum total proteins, albumin, uric acid, calcium, LDH, beta 2 microglobulin, bone marrow plasma cell percentage, serum protein electrophoresis (SPE), serum and urine Immunofixation (IFE) and serum free light chains (FLC) were studied. Clinical history was collected. SPE \& IFE was carried out using agarose gel on automated Genio electrophoresis system, (Interlab). Beta2 microglobulin was measured by immunoturbidimetry on Roche Cobas C6000. Serum Kappa \& Lambda FLC concentrations (using reagents from the Binding site, UK) and immunoglobulin G, A, and $\mathrm{M}$ levels were estimated by immunoturbidimetry on Beckman AU680 analyzer.
Based on the International Myeloma Working Group (ISS) for multiple myeloma, patients were staged as I (Serum beta-2 microglobulin $<3.5 \mathrm{mg} / \mathrm{L}$ and serum albumin $\geq 3.5 \mathrm{~g} / \mathrm{dL}$ ), stage II (Neither stage I nor stage III i.e., beta 2 microglobulin level is between 3.5 and $5.5 \mathrm{mg} / \mathrm{L}$ with any albumin level or Albumin is $<3.5 \mathrm{gm} / \mathrm{dl}$ while beta 2 microglobulin is $<3.5 \mathrm{mg} / \mathrm{L}$ ) \& stage III (Serum beta- 2 microglobulin $\geq 5.5 \mathrm{mg} / \mathrm{L}$ ) [5]. Cytogenetics data are not available for patients, so revised ISS is not used for the classification of patients.

\section{Statistical analysis}

For the comparison of the 3 stages based on International Staging System, the ANOVA test for parametric and Kruskal-Wallis test for non-parametric data was used. Chi square test was used for frequency distribution of MM. Statistical significance assumed to be present if $\mathrm{p}$ value is $<0.05$. Statistical software used was MedCalc Statistical Software version 18.6 [6].

\section{Results}

Of the 94 patients, $38(40.4 \%)$ were female and 56 $(59.6 \%)$ were male. The male to female ratio was 1.47:1. The age of patients ranged from 25 to 78 years with a mean age of 55.5 $\pm 11.78 \mathrm{yrs}$ (females $54.6 \pm 13.4$ years and males is $56.1 \pm 10.6$ years). Fifth decade was found to be the most common age group in our study population.

In our study population we observed that women presented at younger age than in men in stage I \& II and whereas in stage III they presented at older age (Figure 1).

Considering the clinical presentation we found that backache was the most frequent presentation $(30 \%)$ of the patients followed by generalized weakness $(22 \%)$, pathological fractures, joint pains and fever $(8 \%)$ followed by other less frequent presentations like parasthesia, renal failure, bleeding etc as displayed by Figure 2 .

Analyzing the laboratory investigations we found that the stage-wise median (range) of hemoglobin(gm\%) was $12.2,10.2$ and 8.2 in stage I, II and III respectively and the median $\%$ of plasma cells in bone marrow was 39, 67 and 84 respectively, and the difference was statistically significant for both the parameters (Table 1).

The median urea $(\mathrm{mg} / \mathrm{dl})$ level was 26, 31 and 54.5 whereas serum creatinine $(\mathrm{mg} / \mathrm{dl})$ median levels were 0.9 ,

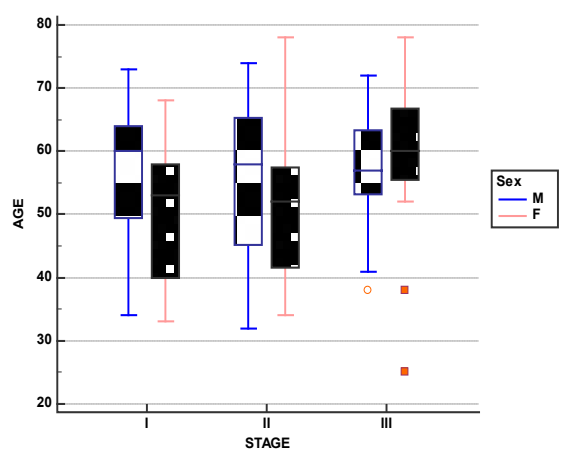

Figure 1. Stage Wise Age and Gender Distribution of Multiple Myeloma Patients 
Table 1. Biochemical Parameters in Different Stages of Multiple Myeloma

\begin{tabular}{|c|c|c|c|c|c|c|c|}
\hline \multirow{2}{*}{$\frac{\text { STAGE }}{\text { Variable }}$} & \multicolumn{2}{|r|}{ I } & \multicolumn{2}{|r|}{ II } & \multicolumn{2}{|r|}{ III } & \multirow[b]{2}{*}{$P$ value } \\
\hline & Mean \pm SD & Median (IQR) & Mean \pm SD & Median (IQR) & Mean \pm SD & Median (IQR) & \\
\hline Urea (mg/dl) & $29.5 \pm 11.9$ & $26(20.8$ to 32.8$)$ & $39.2 \pm 29.9$ & $31(24.5$ to 41.5$)$ & $74.6 \pm 50.3$ & 54.5 (39.5 to 105$)$ & $0.001 *$ \\
\hline Creatinine (mg/dl) & $1.13 \pm 0.51$ & $0.9(0.80$ to 1.20$)$ & $1.28 \pm 1.02$ & $0.95(0.80$ to 1.40$)$ & $2.72 \pm 2.27$ & $2(1.53$ to 2.43$)$ & $<0.001^{*}$ \\
\hline Uric acid (mg/dl) & $4.99 \pm 1.07$ & $5.4(4.4$ to 5.93$)$ & $6.88 \pm 3.5$ & 7.5 (3.95 to 9.15$)$ & $7.59 \pm 2.31$ & $7.2(5.7$ to 9.75$)$ & $0.035^{*}$ \\
\hline Calcium (mg/dl) & $8.9 \pm 0.57$ & $8.8(8.5$ to 9.3$)$ & $9.2 \pm 1.14$ & $9.6(8.8$ to 10.0$)$ & $10.4 \pm 1.99$ & $10.1(9.2$ to 11.7$)$ & $0.004 *$ \\
\hline LDH (U/L) & $373 \pm 115$ & 344 (306 to 426$)$ & $469 \pm 149$ & 434 (367 to 533$)$ & $522 \pm 326$ & 419 (318 to 705$)$ & 0.45 \\
\hline$\beta 2 \mathrm{M}(\mathrm{mg} / \mathrm{L})$ & $2.57 \pm 0.61$ & 2.51 (2.18 to 3.0$)$ & $3.96 \pm 0.79$ & $3.9(3.55$ to 4.58$)$ & $13.12 \pm 8.35$ & 9.897 .24 to 18 & $<0.000^{*}$ \\
\hline Hemoglobin $(\mathrm{gm} / \mathrm{dL})$ & $11.6 \pm 2.4$ & $12.2(9.9$ to 13.5$)$ & $10.2 \pm 1.8$ & $9.9(8.9$ to 11.6$)$ & $8.2 \pm 1.5$ & $7.9(6.9$ to 9.1$)$ & $<0.001^{*}$ \\
\hline$\%$ Plasma cells & $50 \pm 28$ & 3929 to 80 & $57 \pm 30$ & 67 (31 to 81$)$ & $76 \pm 17$ & 84 (62 to 90$)$ & $0.011^{*}$ \\
\hline Total Protein $(\mathrm{gm} / \mathrm{dl})$ & $7.86 \pm 1.37$ & $7.7(7.0$ to 8.4$)$ & $8.06 \pm 1.57$ & 7.65 (7.0 to 8.7$)$ & $8.83 \pm 2.19$ & $8.45(7.45$ to 10.1$)$ & 0.13 \\
\hline Albumin (gm/dl) & $4.12 \pm 0.51$ & $4(3.8$ to 4.4$)$ & $3.47 \pm 0.74$ & 3.4 (3.0 to 3.9 ) & $3.05 \pm 0.79$ & 3 (2.53 to 3.48$)$ & $<0.000^{*}$ \\
\hline Alpha1globulin (gm/dl) & $0.139 \pm 0.047$ & $0.13(0.1$ to 0.17$)$ & $0.177 \pm 0.095$ & $0.16(0.105$ to 0.21$)$ & $0.214 \pm 0.193$ & 0.185 ( 0.11 to 0.22$)$ & 0.46 \\
\hline Alpha2 globulin (gm/dl) & $0.75 \pm 0.121$ & $0.71(0.68$ to 0.82$)$ & $0.7 \pm 0.21$ & $0.65(0.58$ to 0.75$)$ & $0.746 \pm 0.213$ & $0.665(0.593$ to 0.9$)$ & 0.49 \\
\hline Beta globulin (gm/dl) & $1.123 \pm 0.517$ & $0.965(0.80$ to 1.08$)$ & $0.834 \pm 0.29$ & $0.91(0.690$ to 0.95$)$ & $1.053 \pm 0.62$ & $0.9(0.62$ to 1.12$)$ & 0.51 \\
\hline Gamma globulin $(\mathrm{gm} / \mathrm{dl})$ & $1.73 \pm 1.07$ & $1.44(0.87$ to 2.21$)$ & $2.8 \pm 1.57$ & $2.52(1.76$ to 3.71$)$ & $3.45 \pm 2.64$ & $3.69(1.12$ to 4.69$)$ & 0.23 \\
\hline M-protein (gm/dl) & $1.83 \pm 1.21$ & 1.6 (1.28 to 2.42$)$ & $2.85 \pm 1.69$ & $2.5(1.5$ to 4.0$)$ & $3.61 \pm 2.1$ & $3.5(2.24$ to 4.7$)$ & $0.001^{*}$ \\
\hline
\end{tabular}

$\beta_{2} \mathrm{M}$, Beta2 microglobulin; LDH, Lactate dehydrogenase; SD, Standard deviation; IQR, Interquartile range; $* \mathrm{P}$ value $<0.05$ is considered significant

0.95 and 2.0, both increasing across the stages, and the difference was statistically significant.

Calcium $(\mathrm{mg} / \mathrm{dl})$ showed median levels of $8.8,9.6$ and 10.1 and Uric acid $(\mathrm{mg} / \mathrm{dl})$ medians were 5.4, 7.5 and 7.2 respectively. The increase across the stages was statistically significant.

Beta2 microglobulin $(\mathrm{mg} / \mathrm{L})$ median levels were 2.51, 3.9 and 9.89 respectively in stage I, II and III and the increase was statistically significant $(\mathrm{p}=0.000)$.

Though the LDH levels increased from stage I to III, but it was not statistically significant. The median of LDH (U/L) was 344, 434 and 419 from stage I to III. And serum total proteins $(\mathrm{gm} / \mathrm{dl})$ also did not show statistically significant difference .with medians levels of 7.7 (7.0 to $8.4), 7.65$ (7.0 to 8.7$)$ and 8.45 (7.45 to 10.1$)$ in stage I, II and III respectively.

In the variables of serum protein electrophoresis albumin showed significant decrease as the stage is increasing whereas $\mathrm{M}$ protein concentration showed significant increase. The median levels of albumin $(\mathrm{gm} / \mathrm{dl})$ were $4.0,3.4$ and 3.0 whereas the M-protein concentrations $(\mathrm{gm} / \mathrm{dl})$ were $1.6,2.5$ and 3.5 respectively in stages I to III. Other parameters like alpha1, alpha2, beta

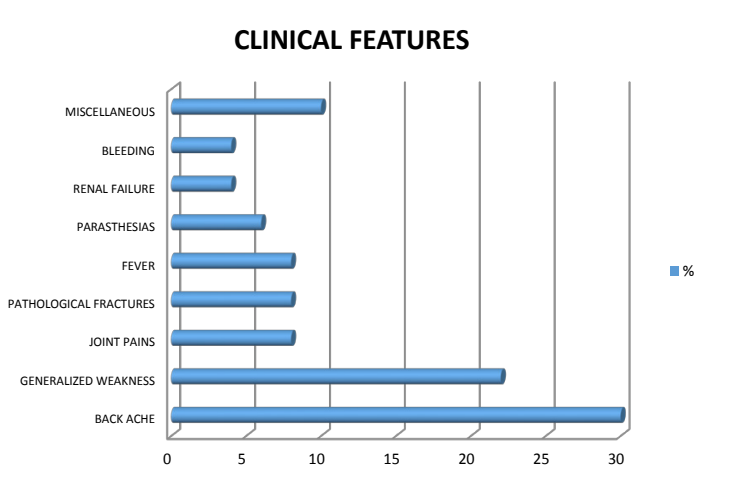

Figure 2. Clinical Features in Percentage of Patients and gamma globulins did not show significant difference in the various stages (Figure 3).

In summary percentage of plasma cells, hemoglobin, urea, creatinine, uric acid, calcium and beta 2 microglobulin showed significant difference across the stages (Table 1). Whereas LDH and total proteins showed increasing trend in stage wise analysis but statistically did not show significant difference.

In case of immunoglobulins $\operatorname{IgG}, \operatorname{IgA}$ and $\operatorname{IgM}$ did not show significant difference in various stages, but IgG showed increasing trend from stage I to III. In case of free light chains only kappa FLC showed significant difference across the stages (Table 2) and this could be due to higher prevalence of kappa type myeloma (69\%) in our subjects.

The patients were staged according to International staging system and were classified according to the types of paraproteins and the majority of the patients $(\mathrm{N}=74$, $78.7 \%$ ) were of $\mathrm{IgG}$ types, 10 of them were of $\mathrm{IgA}$ myeloma (10.8\%), 8 of them were of light chain myeloma $(8.5 \%)$ as shown in Table 3.

Thirty six (36) of the patients were in stage III ( 6 of IgA, 27 of IgG and 3 Light Chains), while 28 patients were in stage II (1of $\operatorname{IgA}, 24 \mathrm{IgG}$ and 3 of Light chains)

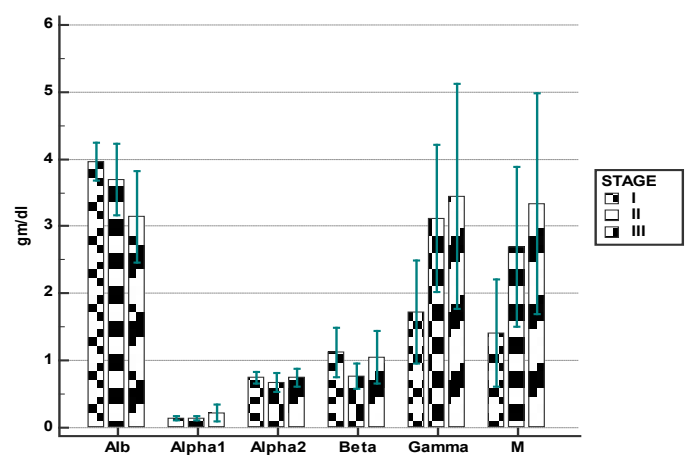

Figure 3. Different Fractions of Serum Protein Electrophoresis in Various Stages of Multiple Myeloma. 
Table 2. Descriptive Statistics of Immunoglobulins and Free Light Chains in Multiple Myeloma Stages

\begin{tabular}{|c|c|c|c|c|c|c|c|}
\hline \multirow[t]{2}{*}{ Variable } & \multicolumn{2}{|c|}{ STAGE I } & \multicolumn{2}{|c|}{ STAGE II } & \multicolumn{2}{|c|}{ STAGE III } & \multirow[t]{2}{*}{$P$ value } \\
\hline & Mean \pm SD & Median (IQR) & Mean \pm SD & Median (IQR) & Mean \pm SD & Median (IQR) & \\
\hline $\operatorname{IgA}(\mathrm{mg} / \mathrm{dl})$ & $3.51 \pm 8.5$ & $0.9(0.5$ to 1.2$)$ & $1.64 \pm 1.76$ & $1.08(0.38$ to 2.28$)$ & $8.1 \pm 14.5$ & $0.71(0.21$ to 9.8$)$ & 0.99 \\
\hline $\operatorname{IgG}(\mathrm{mg} / \mathrm{dl})$ & $25.2 \pm 21.99$ & $22.9(9.3$ to 25.5$)$ & $28.5 \pm 15.5$ & $30.2(16.6$ to 36.3$)$ & $36.7 \pm 30$ & $36.6(5.4$ to 56.2$)$ & 0.67 \\
\hline $\operatorname{IgM}(\mathrm{mg} / \mathrm{dl})$ & $7.6 \pm 19.4$ & 0.33 (0.28 to 0.68$)$ & $0.632 \pm 0.51$ & $0.52(0.29$ to 0.86$)$ & $0.48 \pm 0.46$ & 0.34 (0.21 to 0.45$)$ & 0.49 \\
\hline Kappa FLC (mg/L) & $170.5 \pm 298.3$ & 39.7 (16.2 to 172$)$ & $98.99 \pm 155.4$ & 27.7 (10.9 to 71.3$)$ & $909.6 \pm 2131$ & $165(24.0$ to 875$)$ & $0.048^{*}$ \\
\hline Lambda FLC (mg/L) & $212 \pm 537.3$ & $14.2(8.0$ to 44.0$)$ & $1055.9 \pm 2604.4$ & $25(10.2$ to 412.8$)$ & $1618.7 \pm 5458.3$ & 11.3 (6.34 to 259.9 ) & 0.447 \\
\hline $\mathrm{K} / \mathrm{L}$ ratio & $14.08 \pm 25.53$ & 3.48 (1.31 to 9.74$)$ & $8.7 \pm 17.22$ & $2.13(0.02$ to 9.37$)$ & $79.27 \pm 183.25$ & $26.63(0.20$ to 69.05$)$ & 0.08 \\
\hline
\end{tabular}

and 30 patients were in stage I ( 3 of $\operatorname{IgA}, 23$ of $\operatorname{IgG}, 2$ of IgM and 2 of Light chains) as shown in Table 3.

\section{Discussion}

In the early phase multiple myeloma may be clinically asymptomatic. Appearance of $\mathrm{M}$ components may precede other manifestations by many years [7]. Durie and Salmon analyzed various features of the disease in relation to the total tumor cell mass and correlated them with therapeutic response and survival. They found that the degree of anemia and hypercalcemia, the extent of osteolytic lesions and the serum concentration of $\mathrm{M}$ components correlated well with the neoplastic cell mass. Accordingly, they classified multiple myeloma into three stages. It was found that therapeutic response and survival were best in stage I disease and worst in stage III. Thus, discovery of multiple myeloma should ideally be made in stage I [8]. The clinical manifestations do not completely correspond to the staging; however, they give clues as to when to suspect multiple myeloma. Prognosis depends on several factors; one of them is the stage of the disease at diagnosis.

Early attempts to improve on the DS staging system were not widely adopted. But now, S $\beta 2 \mathrm{M}$ is widely recognized as the single most important variable predicting survival. When added to $\mathrm{S} \beta 2 \mathrm{M}$, serum albumin level was known to add significantly to prognostication. This led to an $\mathrm{S} \beta 2 \mathrm{M}$ and serum albumin staging system, developed by the Southwest Oncology Group. The newly developed and proposed ISS system [5] thus extends and validates these prior observations. Several cases of myeloma go undiagnosed each year, due to the shortage of medical facilities in the rural India. Comparative statistics of biochemical parameters on the various stages of multiple myeloma are rare.

The age of the patients found in our study group ranged from 25 to $78 y$ rs, with a median age of $57 \mathrm{yrs}$, making it necessary for the clinician to keep this in the differential diagnosis, whenever appropriate, for this entire age range. Our median is a little higher than the median age of 55 years reported in National Cancer Registry Programme statistics [9]. On the other hand the mean age in our study was 55.5 years matching with that of Wadhwa et al, [10] (55.4 yrs), whereas Advani et al., [11] have reported mean age 51 years. In our study, mean age in years were 54.3, 53.9 and 57.7 respectively in stages I, II \& III and the difference was not statistically significant.

The male to female ratio was $1.47: 1$. The male preponderance in our study concurs with previous studies. Tripathy et al, [12] reported that the disease manifested in the later ages in females (61 to 70 years) than in the male patients (51 to 60 years). In our stage-wise analysis females presented at younger age in stages I (mean age of females is 50yrs and males is 56.5yrs) \& II ( F =52.4 and $\mathrm{M}=55.3 \mathrm{yrs}$ ), whereas in stage III, females (mean age of 59.5yrs) were older than males (56.4yrs).

We observed that the most common clinical presentation (46\%) was bone related such as low backache, bone pain, joint pains and pathological fractures similar to another Indian study [13]. Clinical history taken in our patients showed majority with back ache with bone pain as the chief complaint $(30 \%)$. Bone pains were chief complaints by the patients in the studies published

Table 3. Frequency Table of Type of Multiple Myeloma in Various Stages

\begin{tabular}{lcccccccc}
\hline \multicolumn{1}{c}{ STAGE } & \multicolumn{9}{c}{ TYPE OF MULTIPLE MYELOMA } \\
\hline I & IGAK & IGAL & IGGK & IGGL & IGMK & KLC & LLC & \\
II & 3 & 0 & 19 & 4 & 2 & 0 & 2 & $30(31.9 \%)$ \\
III & 1 & 0 & 17 & 7 & 0 & 0 & 3 & $28(29.8 \%)$ \\
& 5 & 1 & 16 & 11 & 0 & 2 & 1 & $36(38.3 \%)$ \\
& 9 & 1 & 52 & 22 & 2 & 2 & 6 & 94 \\
Chi-squared & 15.802 & $(1.1 \%)$ & $(55.3 \%)$ & $(23.4 \%)$ & $(2.1 \%)$ & $(2.1 \%)$ & $(6.4 \%)$ & \\
DF & 12 & & & & & & & \\
Sig. level & $\mathrm{P}=0.2005$ & & & & & & & \\
\hline
\end{tabular}

IGAK, Immunoglobulin A kappa; IGAL, Immunoglobulin A lambda; IGGK, Immunoglobulin G kappa; IGGL, Immunoglobulin G lambda; IGMK, Immunoglobulin M kappa; KLC, Kappa light chain disease; LLC, Lambda light chain disease. P value $<0.05$ is considered significant. 
by Kaur et al, [14] (50\%), Gupta et al, [15] (79\%) and Kyle et al, [16] (58\%). This is followed by generalized weakness and fatigability (22\%). Generalized weakness and fatigability were recorded in $46.4 \%$ in Kaur et al, [14] and in $32 \%$ in a study at Mayo clinic [17] and is attributable to anemia. Bony pains and easy fatigability were also the most common symptoms in another study by Subramanian [18]. Pathological fractures, joint pains and fever presented in $8 \%$ of patients.

The number of patients diagnosed as ISS III was higher in our study (38.3\%) as compared to the data from Jacob LA et al, [19] which showed 39\%. In Western data (percentage of patients in ISS III was 18\%); the maximum numbers of patients were in ISS II [16]. Cytogenetics data are not available for patients, so revised ISS is not used for the classification of patients.

The most commonly occurring paraprotein type is $\mathrm{IgG}$, followed by IgA and light-chain myelomas. Our results showed $79 \%$ patients with IgG myeloma, 18\% patients with $\operatorname{IgA}$ and $9.6 \%$ patients with light chain myeloma. Wang et al [20] found IgG myeloma in 56\% patients and IgA myeloma in $25 \%$ patients. The number of patients with IgG type of myeloma was $72 \%$ as per the data from Jacob LA et al., [19], and more than 50\% from Mayo Clinic [17]. The variation of IgA and light chain myeloma in our series may be due to racial and environmental variations or may be due to small size sample.

We found five different patterns of paraprotein fractions, where $\operatorname{IgG} \kappa$ constituted $70 \%$ which was most common, other fraction were $\operatorname{IgG} \lambda(10 \%), \operatorname{IgM} \kappa(10 \%)$, $\operatorname{IgA} \kappa(5 \%)$ and $\operatorname{IgA} \lambda(5 \%)$. We found $30(31.9 \%)$ cases in stage I with maximum of $\operatorname{IgGK}(\mathrm{n}=19)$ followed by $\mathrm{IgGL}$ $(n=4), \operatorname{IgAK}(n=3), \operatorname{IgMK}(n=2)$ and 2 cases of Lambda Light chain disease. In stage II maximum cases were of $\operatorname{IgGK}(n=17)$ followed by $\operatorname{IgGL}(n=7)$, LLC disease $(n=3)$ and $\operatorname{IgAK}(n=1)$. In the stage III, the cases were in the order of $\operatorname{IgGK}(\mathrm{n}=16), \operatorname{IgGL}(\mathrm{n}=11), \operatorname{IgAK}(\mathrm{n}=5), \mathrm{KLC}$ disease $(n=2)$, each of LLC and IgAL (Table 3$)$.

In our study, $89 \%$ cases demonstrated monoclonal protein, while in Kyle study [16] serum protein electrophoresis study revealed $\mathrm{M}$ band in $82 \%$ of patients and Kaur et al [14] reported it in $92.8 \%$. In our study the band migrated in gamma region in $83 \%$, in other ranges such as beta $(5.8 \%)$, alpha $2(1.06 \%)$ and between gamma and beta ( $9 \%$ ), and case of biclonal gammopathy (1.06\%). $\mathrm{M}$ band was not seen in $11 \%$ of patients and we feel that all clinicians must be aware of the fact that $\mathrm{M}$ band won't be seen in all cases.

There was significant increase $(p=0.001)$ in concentration of M-protein in 3 stages which were 1.83 , 2.85 and $3.61 \mathrm{gm} / \mathrm{dl}$ respectively.

The mechanism of anemia in most patients is inadequate production of red blood cells due to either erythropoietin deficiency or pronounced marrow replacement by myeloma cells or from accompanying renal failure [16]. Our study also supports this finding by showing the decrease in hemoglobin and increase in bone marrow plasma cells as the stage increases. In some patients anemia is disproportionate to renal failure or marrow involvement and is thought to be due to cytokine mediated marrow suppression.

Biochemical data helps to assess tumor mass and renal involvement. In this study the serum creatinine level was increased as stage is increasing which was statistically significant. The major cause of renal failure is myeloma nephropathy (precipitation of monoclonal light chains in distal and collecting tubules). Other causes include dehydration and hyperuricemia [16]. Hyperuricemia was noted, uric acid increasing as the stage is progressing which was statistically significant. Serum Albumin has also been identified as a reliable prognostic factor in various studies. Elevated beta 2 microglobulin levels have been repeatedly shown to have independent prognostic value in myeloma [21, 22].

Hypercalcemia, even though considered as one among the important diagnostic criteria (CRAB symptoms), in our study mean values were not high in different stages. Kyle et al [16] also reported hypercalcemia only among $13 \%$ of the 1027 patients. In their study diagnosis of MM was made in those with normal calcium 21 (66\%) and below normal levels 5 (16\%). Low calcium levels might be due to renal impairment. Hypocalcemia in MM secondary to Vitamin D deficiency was reported previously [23]. Factors including vitamin D deficiency may be contributing to hypocalcemia other than renal failure in myeloma patients.

Serum LDH is a simple, inexpensive and readily available blood test, which identifies a subset of patients with poor outcome. Our data suggests that as the stage is progressing $\mathrm{LDH}$ also is increasing. In a multivariate analysis, elevated serum LDH was found to be an independent factor and had a major prognostic impact associated with a 5.4-fold increased risk for death [24]. Further they suggested that the elevated baseline serum LDH should be included in the current criteria (i.e. poor risk cytogenetics, high plasma cell labeling index) which are being used to characterize high risk myeloma. The revised International Staging System(R-ISS) [25] has been developed that incorporates the original staging system with chromosomal abnormalities and serum lactate dehydrogenase.

In conclusion, having baseline data on the varied laboratory characteristics of a disease is of immense help to clinicians in the diagnosis and prognosis of that disease. It also helps laboratorians in their reporting work. MM is a disease affecting 2.1 per 100,000 of world population [26] and 1.2 to 1.8 per 100,000 of Indian population [27]. However there is paucity of data on laboratory parameters in various stages of MM, especially in India. Our study made a beginning to fill this gap by collating the data of age, sex, type of myeloma, biochemical parameters (urea, creatinine, uric acid, calcium, LDH, total proteins, albumin, globulins, immunoglobulins and M-protein) and FLC etc as well as the presenting data across different stages of MM. We have particularly shown that male preponderance with a male to female ratio of $1.47: 1$. The overall mean age was 55.5 years in the present study, with the mean age of presentation being 54.3, 53.9 and 57.7 years respectively in ISS stages I, II \& III. Most common clinical presentation (46\%) was bone related such 
as low backache, bone pain, joint pains and pathological fractures and most of our patients presented in advanced clinical stage in stage III. The most commonly occurring paraprotein type is $\operatorname{IgG}$, followed by $\operatorname{IgA}$ and light-chain myelomas. The presentation of MM is nonspecific and patient can come with varied presentations at onset. The quality of life and survival in MM patients can be improved significantly if detected early in stage I and II.

We hope that the information presented in this study will form a basis for clinicians and other laboratorians to plan further studies including large prospective cohorts on these lines and develop stage-based algorithms for early and better diagnosis and prognosis of MM.

\section{Acknowledgements}

This research did not receive any specific grant from funding agencies in the public, commercial, or not-forprofit sectors.

The authors declare no conflict of interest

\section{References}

1. Fousad C, Gangadharan K V, Abdulla MC, Naryan R, Mohammed Ali M J. Clinical profile of multiple myeloma in South India. Indian J Med Paediatr Oncol, 2018; 39, 62-6.

2. Diwan AG, Gandhi SA, Krishna K, Shinde VP. Clinical profile of the spectrum of multiple myeloma in a teaching hospital. Med J DY Patil Univ, 2014; 7, 185-8.

3. AJ Madu, S Ocheni, TA Nwagha, OG Ibegbulam, US Anike.: Multiple myeloma in Nigeria: An insight to the clinical, laboratory features, and outcomes. Nigerian Journal of Clinical Practice, 2014; Mar-Apr.Vol 17, Issue 2, page212-17.

4. Kyle and Rajkumar, Criteria for diagnosis, staging, risk stratification and response assessment of multiple myeloma. Leukemia, 2009; 23: 3-9.

5. Greipp PR, San Miguel J, Durie BG, et al: International staging system for multiple myeloma. J Clin Oncol, 2005; 23, 3412-20.

6. MedCalc Software bvba, Ostend, Belgium; http://www. medcalc.org; 2018.

7. Kyle RA, Bayrd ED: Benign monoclonal gammopathy: a potentially malignant condition? Am I Med, 1966; 40, 426.

8. Durie BG, Salmon SE. A clinical staging system for multiple myeloma. Correlation of measured myeloma cell mass with presenting clinical features, response to treatment, and survival. Cancer, 1975; Sep; 36 (3), 842-54.

9. NCRP, 2001: National cancer registry programme. Consolidated report of population based cancer registries 1990-1996. ICMR New Delhi.

10. Wadhwa J et al. Multiple myeloma: A retrospective analysis of 534 patients. Dissertation topic. All India Institute of Medical Sciences (AIIMS), 1999; New Delhi, India.

11. Advani SH, Soman CS, Talwalkar GV, Lyer YS, Bhatia HM. Multiple-myeloma: review of 231 cases. Indian J Cancer, 1978; Jun, 15 (2), 55-61.

12. Tripathy S. The Role of Serum Protein Electrophoresis in the Detection of Multiple Myeloma. Journal of Clinical and Diagnostic Research, 2012;. November, Vol 6 (9): 1458-61.

13. Sridhar S, Dutta TK, Basu D. Clinical profile of multiple myeloma and effect of thalidomide based treatment on its outcome. J Indian Med Assoc, 2011; 109,880-2, 887-8.

14. Kaur P, Shah BS, Baja P. Multiple myeloma: a clinical and pathological profile. Gulf J Oncolog, 2014; 1, 14-20.

15. Gupta P, Kochupillai V et al. A 12 tears study of multiple myeloma at AIIMS, Ind J Med \& Ped Oncol, 1995; Vol 16, 108-14.

16. Kyle RA, Gertz MA, Witzig TE, et al. Review of 1027 patients with newly diagnosed multiple myeloma. Mayo Clinic Proc, 2003; 78, 21-33.

17. Attal M, Lauwers-Cances V, Hulin C, Facon T, Caillot D, Escoffre M, et al. Autologous transplantation for multiple myeloma in the era of new drugs: A phase III study of the Intergroupe Francophone du Myelome (IFM/DFCI 2009 Trial). Blood, 2015; 126, 391.

18. Subramanian R, Basu D, Dutta TK. Prognostic significance of bone marrow histology in multiple myeloma. Indian $\mathrm{J}$ Cancer, 2009; 46, 40-5.

19. Jacob LA, Suresh Babu M C, Lakshmaiah K C, Babu K G, Lokanatha D etal. Multiple myeloma: Experience of an institute in limited resource setting. Indian J Cancer, 2017; 54, 340-2.

20. Wang L, Wang KF, Chang BY, Chen XQ, Xia ZJ. Onceweekly subcutaneous administration of bortezomib in patients with multiple myeloma. Asian Pac J Cancer Prev, 2015; 16, 2093-8.

21. Durie BGM, Stock-Novack D, Salmon SE, et al. Prognostic value of pretreatment serum beta2 microglobulin in myeloma: A Southwest Oncology Group study. Blood, 1990; 75, 823-30.

22. Bataille R, Durie BGM, Grenier J. Serum beta 2 microglobulin and survival duration in multiple myeloma: A simple reliable marker for staging. Br J Haematol, 1983; 55, 439-47.

23. Ramasamy I.Hypocalcemia in multiple myeloma secondary to unrecognised Vitamin D deficiency: A case report. Bone, 2011; 48: S27-8.

24. Dimopoulos, M. A., Kastritis, E., Roussou, M., Gkotzamanidou, M., Migkou, et al. Elevated Serum Lactate Dehydrogenase (LDH) Should Be Included Among the Variables Which Define High Risk Multiple myeloma. Blood, 2010; 116(21), 2969.

25. Palumbo, A., H. Avet-Loiseau, S. Oliva, H. M. Lokhorst, H. Goldschmidt, L.et al. Revised International Staging System for Multiple Myeloma: A Report From International Myeloma Working Group. J ClinOncol, 2015; 33, (26), 2863-9.

26. Cowan AJ, Allen C, Barac A, et al.. Global Burden of Multiple Myeloma: A Systematic Analysis for the Global Burden of Disease Study. JAMA Oncol, 2018; 4 (9), 1221-7.

27. Kumar L.. Multiple Myeloma - The Indian Perspectives: Current situation. Comy, 2nd world congress, 2016.

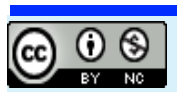

This work is licensed under a Creative Commons AttributionNon Commercial 4.0 International License. 